\title{
The Use of Air in the Inspired Gas Mixture During Two-Lung Ventilation Delays Lung Collapse During One-Lung Ventilation
}

\author{
Raynauld Ko, MD* \\ BACKGROUND: Collapse of the ipsilateral lung facilitates surgical exposure during \\ thoracic procedures. The use of different gas mixtures during two-lung ventilation \\ Karen McRae, MDCM* \\ (2LV) may improve or impede surgical conditions during subsequent one-lung \\ ventilation (OLV) by increasing or delaying lung collapse. We investigated the \\ Gail Darling, MD† \\ Thomas K. Waddell, MD, PhD十 \\ 作 \\ during subsequent OLV: Air/Oxygen (fraction of inspired oxygen $\left[\mathrm{FTO}_{2}\right]=0.4$ ), \\ Nitrous Oxide/Oxygen (" $\mathrm{N}_{2} \mathrm{O}$," $\mathrm{FTO}_{2}=0.4$ ) and Oxygen (" $\mathrm{O}_{2}$," $\mathrm{FiO}_{2}=1.0$ ). \\ Desmond McGlade, MBBS \\ METHODS: Subjects were randomized into three groups: Air/Oxygen $(n=33)$, \\ $\mathrm{N}_{2} \mathrm{O}(n=34)$ or $\mathrm{O}_{2}(n=33)$ and received the designated gas mixture during \\ induction and until the start of OLV. Subjects' lungs in all groups were then \\ FANZCA* \\ ventilated with $\mathrm{FrO}_{2}=1.0$ during OLV. The surgeons, who were blinded to the \\ randomization, evaluated the lung deflation using a verbal rating scale at 10 \\ Ken Cheung, $\mathrm{MD}^{*}$ \\ Joel Katz, PhD* \\ and $20 \mathrm{~min}$ after the start of OLV. Serial arterial blood gases were performed \\ before anesthesia induction, during $2 \mathrm{LV}$, and every $5 \mathrm{~min}$, for $30 \mathrm{~min}$, after \\ initiation of OLV. \\ RESULTS: The use of air in the inspired gas mixture during 2LV led to delayed lung \\ deflation during OLV, whereas $\mathrm{N}_{2} \mathrm{O}$ improved lung collapse. Arterial oxygenation \\ was significantly improved in the $\mathrm{O}_{2}$ group only for the first $10 \mathrm{~min}$ of OLV, after \\ which there were no differences in mean $\mathrm{PaO}_{2}$ values among groups. \\ CONCLUSIONS: De-nitrogenation of the lung during $2 \mathrm{LV}$ is a useful strategy to \\ improve surgical conditions during OLV. The use of $\mathrm{FrO}_{2} 1.0$ or $\mathrm{N}_{2} \mathrm{O} / \mathrm{O}_{2}\left(\mathrm{FrO}_{2} 0.4\right)$ \\ during $2 \mathrm{LV}$ did not have an adverse effect on subsequent oxygenation during OLV.
}

$T_{\text {he }}$

he primary indication for one-lung ventilation (OLV) is to facilitate surgical exposure in the chest by collapsing the ipsilateral lung. Thus, anesthetic techniques which delay lung collapse may impede thoracic surgery. Studies of OLV in sheep have demonstrated that two mechanisms are primarily involved in the determination of rate of collapse of the nonventilated lung. ${ }^{1}$ The first mechanism is passive exhalation from the inherent elastic recoil of the lung. However, this passive exhalation is usually over within $60 \mathrm{~s}$ of lung isolation and any means to further deflate, such as with an increase in pleural pressure or suctioning of the airway, failed due to small airway closure. Uptake of

From the Departments of *Anesthesia and Pain Management, and + Surgery, Division of Thoracic Surgery, Toronto General Hospital, University Health Network, University of Toronto, Ontario, Canada. residual lung gases or absorption atelectasis is a second mechanism of lung collapse during OLV. Thus, efforts to promote lung collapse will primarily occur via changing the rate of gaseous uptake in the alveoli. There have been no human studies that have evaluated the effects of inspired gas mixtures on lung collapse during thoracic surgery.

Nitrogen may delay the development of atelectasis because it is not as easily absorbed into the bloodstream as oxygen $\left(\mathrm{O}_{2}\right)$ or nitrous oxide $\left(\mathrm{N}_{2} \mathrm{O}\right){ }^{2}$ While potentially delaying lung collapse, the use of air in the inspired gas mixtures during two-lung ventilation (2LV) may improve oxygenation during subsequent OLV by decreasing the rate atelectasis formation in the ventilated lung. ${ }^{3-5}$ Indeed, Agarwal et al. ${ }^{6}$ describe improved gas exchange in healthy patients' lungs undergoing general anesthesia when the patients are ventilated with fraction of inspired oxygen $\left(\mathrm{FiO}_{2}\right) 0.4$ instead of $\mathrm{FIO}_{2} 1.0$ postintubation. There has been a recent trend to replace the conventional use of $\mathrm{N}_{2} \mathrm{O} / \mathrm{O}_{2}$ mixtures with air/oxygen mixtures during general anesthesia. ${ }^{7,8}$

The hypothesis of this study was that the use of nitrogen-containing air in the inspired gas mixture during 2LV delays lung collapse during subsequent OLV. We also hypothesized that the use of air or $\mathrm{N}_{2} \mathrm{O}$ 
in the inspired gas mixture during $2 \mathrm{LV}$ would affect arterial oxygenation during subsequent OLV with a $\mathrm{FIO}_{2}=1.0$.

\section{METHODS}

After hospital Research Ethics Board approval and after obtaining written consent, patients scheduled for elective thoracotomy or thoracoscopic surgery for lung cancer were allocated by random number assignment to one of three study groups: "AIR," " $\mathrm{N}_{2} \mathrm{O}^{\prime}$ or " $\mathrm{O}_{2}$ ". Subjects were consecutive consenting adult patients of the two participating thoracic surgeons (GD and TW) scheduled for surgery in the lateral decubitus position, with an expected duration of OLV to exceed $30 \mathrm{~min}$, and who had no contraindications to the study protocol. All patients had preoperative spirometry. Patients were excluded if difficulty in airway management was anticipated on preoperative assessment or they had evidence of bullae on chest radiographs or major medical co-morbidities.

During induction and maintenance of anesthesia, the AIR group received an inspired gas mixture of $\mathrm{O}_{2}$ and air $\left(\mathrm{FIO}_{2} 0.40\right)$, the $\mathrm{N}_{2} \mathrm{O}$ group received a gas mixture of $\mathrm{O}_{2}$ and $\mathrm{N}_{2} \mathrm{O}\left(\mathrm{FIO}_{2} 0.40\right)$ and the $\mathrm{O}_{2}$ group received $100 \% \mathrm{O}_{2}$. Patients received total IV anesthesia to avoid the possible confounding effects of inhaled volatile anesthetic concentrations on oxygenation during OLV. The selected inspired gas mixture was titrated to a total fresh gas flow of $8 \mathrm{~L}$ per minute. Anesthesia induction was achieved with $2-3 \mu \mathrm{g} / \mathrm{kg}$ fentanyl, $2 \mathrm{mg} / \mathrm{kg}$ propofol, and $1 \mathrm{mg} / \mathrm{kg}$ of rocuronium. Anesthesia was maintained with propofol $120-200 \mu \mathrm{g} \cdot \mathrm{kg}^{-1} \cdot \mathrm{min}^{-1}$ infusion and intermittent boluses of rocuronium $0.15-0.3 \mathrm{mg} / \mathrm{kg}$ based on trainof-four neuromuscular monitoring.

Tidal volumes were $10 \mathrm{~mL} / \mathrm{kg}$ ideal body weight during both $2 \mathrm{LV}$ and OLV without positive endexpiratory pressure (PEEP). The selected gas mixture was introduced by mask during induction and continued during positive pressure ventilation until the start of OLV. The patients' airways were intubated with an appropriate-size left-sided double-lumen endobronchial tube (DLT) and the position of the DLT was confirmed with fiberoptic bronchoscopy (FOB). After induction of anesthesia, the FOB was repeated by the surgeon via the DLT and a cervical mediastinoscopy was performed in the supine position if required for cancer staging. The patients were then turned to the lateral position and the position of the DLT was confirmed and adjusted as needed by FOB. OLV of the dependent lung was begun in the lateral position, immediately before opening the nondependent lung pleura, by inflation of the bronchial cuff of the DLT and clamping the lumen of the DLT to the nonventilated lung proximally. The distal port of the DLT lumen was then opened to atmosphere and the adequacy of lung isolation was confirmed by monitoring the inspired and expired tidal volumes using the sidestream spirometer of the anesthetic machine (ADU-S5,
GE-Datex/Ohmeda, Madison, WI). During OLV, all patients' lungs were ventilated with a $\mathrm{FIO}_{2}=1.0$.

\section{Measurements}

Arterial blood gases were obtained while the patient was breathing room air prior to anesthesia induction, during $2 \mathrm{LV}$ in the lateral position, and every 5 min for the first $30 \mathrm{~min}$ of OLV to document the time at which the $\mathrm{PaO}_{2}$ values became equivalent in the groups. The time, $\mathrm{FO}_{2}$, arterial $\mathrm{O}_{2}$ saturation, end-tidal carbon dioxide, heart rate, and arterial blood pressure were also noted for each blood gas determination. If arterial $\mathrm{O}_{2}$ saturation decreased below $90 \%$, the DLT was checked for malpositioning with FOB and a recruitment maneuver (a sustained inflation of the lung to $25 \mathrm{~cm} \mathrm{H}_{2} \mathrm{O}$ pressure for $20 \mathrm{~s}$ ) of the ventilated lung was performed. ${ }^{9}$

The surgeons were blinded to the gas mixtures inspired by the patients. The surgeons did not divide the pulmonary vasculature before the end of $20 \mathrm{~min}$ of OLV in order to minimize the surgical effects on lung collapse and shunt fraction. Surgeons were instructed to provide a lung deflation score at 10 and $20 \mathrm{~min}$ after the initiation of OLV using a nonparametric verbal rating scale for lung deflation from zero (corresponding to no lung deflation) up to 10 (corresponding to maximal lung deflation). All data were recorded manually by the supervising anesthesiologist on a standardized study case report form and later transferred to a computerized database.

\section{Data Analysis}

The sample size of the study was calculated based on previously published data showing a mean $\mathrm{PaO}_{2}$ during OLV of approximately $220 \mathrm{~mm} \mathrm{Hg}$ with a SD of $100 \mathrm{~mm} \mathrm{Hg}{ }^{10}$ Using an assumed clinically relevant difference in mean $\mathrm{PaO}_{2}$ levels during OLV among groups of $50 \mathrm{~mm} \mathrm{Hg}$, a minimum of 33 subjects were required per group to achieve an $\alpha$ of 0.05 with a $\beta$ of 0.2 . The data collected were entered into a Microsoft Access database and then analyzed with SPSS v11.0 statistical software package. Data were analyzed by two-way analysis of variance and significant effects were followed up with separate Mann-Whitney tests for nonparametric variables and Fisher's tests for parametric variables.

\section{RESULTS}

One-hundred patients were enrolled into the study (AIR $n=33, \mathrm{~N}_{2} \mathrm{O}=34, \mathrm{O}_{2}=33$ ). Demographic data and other information are listed in Table 1 . There were no differences among the three study groups with respect to preoperative lung function, type of surgery, side of surgery or time from induction to OLV.

Lung deflation scores for the three groups at the different study time periods are shown in Figure 1. Lung deflation scores were lower in the AIR group indicating less lung collapse at both 10 and $20 \mathrm{~min}$ after initiation of OLV compared with the $\mathrm{N}_{2} \mathrm{O}$ and $\mathrm{O}_{2}$ 


\begin{tabular}{|c|c|c|c|}
\hline & AIR & Nitrous oxide & Oxygen \\
\hline No. of cases & 33 & 34 & 33 \\
\hline Gender: male/female & $15 / 18$ & $15 / 19$ & $18 / 15$ \\
\hline Age $(y r)$ & $64 \pm 12$ & $65 \pm 14$ & $65 \pm 11$ \\
\hline Weight $(\mathrm{kg})$ & $73.5 \pm 28.5$ & $77.2 \pm 22.0$ & $73.5 \pm 23.5$ \\
\hline Height $(\mathrm{cm})$ & $164 \pm 12$ & $168 \pm 13$ & $165 \pm 18$ \\
\hline Time to one lung ventilation (min) & $66 \pm 40$ & $64 \pm 32$ & $65 \pm 35$ \\
\hline \multicolumn{4}{|l|}{ Surgical procedure } \\
\hline $\mathrm{R}$ thoracotomy (wedge/segmentectomy) & 1 & 2 & 0 \\
\hline $\mathrm{R}$ thoracotomy (lobectomy) & 16 & 18 & 20 \\
\hline $\mathrm{R}$ thoracotomy (pneumonectomy) & 1 & 1 & 3 \\
\hline R VATS & 3 & 0 & 0 \\
\hline L thoracotomy (wedge/segmentectomy) & 0 & 0 & 0 \\
\hline L thoracotomy (lobectomy) & 12 & 11 & 8 \\
\hline L thoracotomy (pneumonectomy) & 0 & 1 & 0 \\
\hline L VATS & 0 & 1 & 2 \\
\hline Mediastinoscopy (added to procedure) & 6 & 4 & 3 \\
\hline \multicolumn{4}{|l|}{ Pulmonary function tests } \\
\hline FEV1 (\% of predicted) & $83 \pm 24$ & $81 \pm 22$ & $83 \pm 28$ \\
\hline FVC (\% of predicted) & $88 \pm 24$ & $82 \pm 21$ & $87 \pm 25$ \\
\hline FEV1/FVC & $80 \pm 14$ & $78 \pm 14$ & $83 \pm 15$ \\
\hline RV (\% of predicted) & $133 \pm 38$ & $122 \pm 33$ & $131 \pm 35$ \\
\hline FRC (\% of predicted) & $133 \pm 29$ & $123 \pm 25$ & $125 \pm 26$ \\
\hline \multicolumn{4}{|l|}{ Arterial blood gas on room air } \\
\hline $\mathrm{pH}$ & $7.42 \pm 0.03$ & $7.43 \pm 0.03$ & $7.43 \pm 0.03$ \\
\hline $\mathrm{PaCO}_{2}(\mathrm{~mm} \mathrm{Hg})$ & $39.5 \pm 3.5$ & $39.8 \pm 3.6$ & $40.2 \pm 3.1$ \\
\hline $\mathrm{PaO}_{2}(\mathrm{~mm} \mathrm{Hg})$ & $88 \pm 12$ & $91 \pm 10$ & $87 \pm 13$ \\
\hline
\end{tabular}

There were no significant differences for any of these variables among groups.

VATS $=$ video-assisted thoracoscopic surgeny; FEV $=$ forced expiratory volume at $1 \mathrm{~s} ; F \mathrm{FC}=$ forced vital capacity (lung function test); RV $=$ residual volume; $F R C=$ functional residual capacity.

\section{Lung Deflation Score}

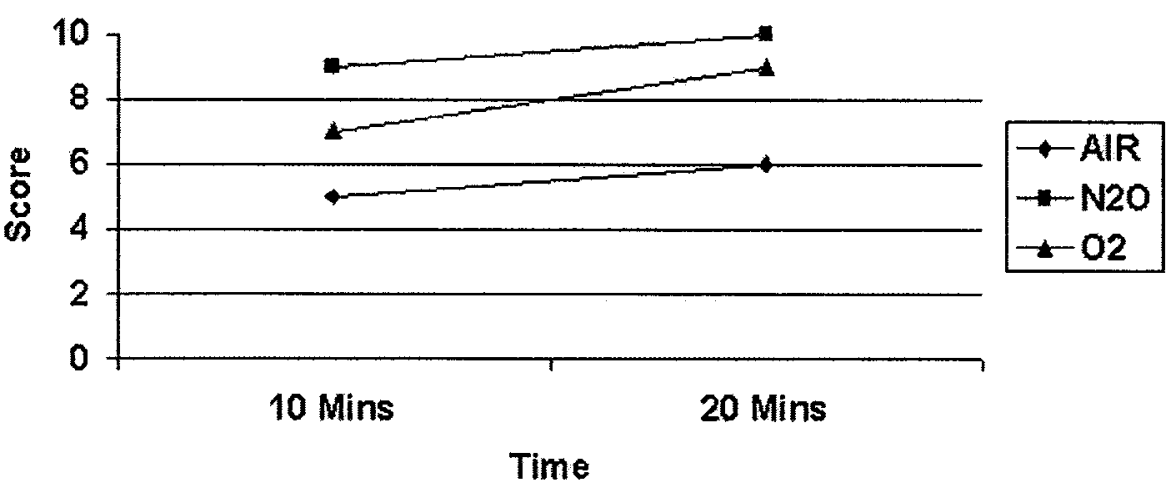

Figure 1. Median Lung Deflation Score vs Time after the start of one-lung ventilation (OLV). A Lung Deflation Score of 0 equals no lung collapse while a score of 10 equals complete lung collapse. Lung deflation scores in the AIR group were significantly lower compared to the nitrous oxide $\left(\mathrm{N}_{2} \mathrm{O}\right)$ and oxygen $\left(\mathrm{O}_{2}\right)$ groups at $10 \mathrm{~min}$ and 20 min after initiation of $\mathrm{OLV}$ $(P<0.008)$. Lung deflation scores in the $\mathrm{N}_{2} \mathrm{O}$ group where higher compared with the $\mathrm{O}_{2}$ Group 10 min $(P<0.002)$ but not $20 \mathrm{~min}(P=0.32)$ after initiation of OLV. AIR $(n=33)$ : Air $/ \mathrm{O}_{2} \mathrm{FrO}_{2} 0.4$ during two-lung ventilation (2LV); then fraction of inspired oxygen $\left(\mathrm{FIO}_{2}\right) 1.0$ during OLV. $\mathrm{N}_{2} \mathrm{O}(n=34): \mathrm{N}_{2} \mathrm{O} / \mathrm{O}_{2} \mathrm{FIO}_{2} 0.42 \mathrm{LV}$; then $\mathrm{FIO}_{2} 1.0$ OLV O $2(=33)$ : FIO $1.02 \mathrm{LV}$; and $\mathrm{FIO}_{2}$ 1.0 OLV.

groups. The median lung deflation scores at $10 \mathrm{~min}$ of OLV were: $\mathrm{AIR}=5$ versus $\mathrm{N}_{2} \mathrm{O}=9$ and $\mathrm{O}_{2}=7(P<$ 0.008). After 20 min of OLV the median lung deflation scores were: $\mathrm{AIR}=6$ versus $\mathrm{N}_{2} \mathrm{O}=10, \mathrm{O}_{2}=9(P<$ $0.008)$. Lung deflation scores in the $\mathrm{N}_{2} \mathrm{O}$ group were significantly improved compared with the $\mathrm{O}_{2}$ group after $10 \mathrm{~min}$ of OLV $(P<0.002)$, but they were not different after $20 \mathrm{~min}$ of OLV $(P=0.032)$.

There were no significant differences in mean $\mathrm{PaO}_{2}$ values at baseline among the three study groups
(Table 1). Arterial oxygenation at the different study time periods is shown in Figure 2. The $\mathrm{O}_{2}$ group had a higher $\mathrm{PaO}_{2}$ during $2 \mathrm{LV}$ in the lateral position compared with the AIR and $\mathrm{N}_{2} \mathrm{O}$ groups (AIR $=160$ $\mathrm{mm} \mathrm{Hg}, \mathrm{N}_{2} \mathrm{O}=188 \mathrm{~mm} \mathrm{Hg}, \mathrm{O}_{2}=411 \mathrm{~mm} \mathrm{Hg} ; P<$ 0.001 ). After 5 and $10 \mathrm{~min}$ of OLV, the $\mathrm{O}_{2}$ group still had a higher $\mathrm{PaO}_{2}$ compared with the other groups (5 $\min : \mathrm{AIR}=198 \mathrm{~mm} \mathrm{Hg}, \mathrm{N}_{2} \mathrm{O}=213 \mathrm{~mm} \mathrm{Hg}, \mathrm{O}_{2}=337$ $\mathrm{mm} \mathrm{Hg} ; P<0.001 ; 10 \mathrm{~min}: \mathrm{AIR}=188 \mathrm{~mm} \mathrm{Hg}, \mathrm{N}_{2} \mathrm{O}=$ $\left.190 \mathrm{~mm} \mathrm{Hg}, \mathrm{O}_{2}=264 \mathrm{~mm} \mathrm{Hg} ; P=0.005\right)$. This 


\section{Arterial Oxygenation}

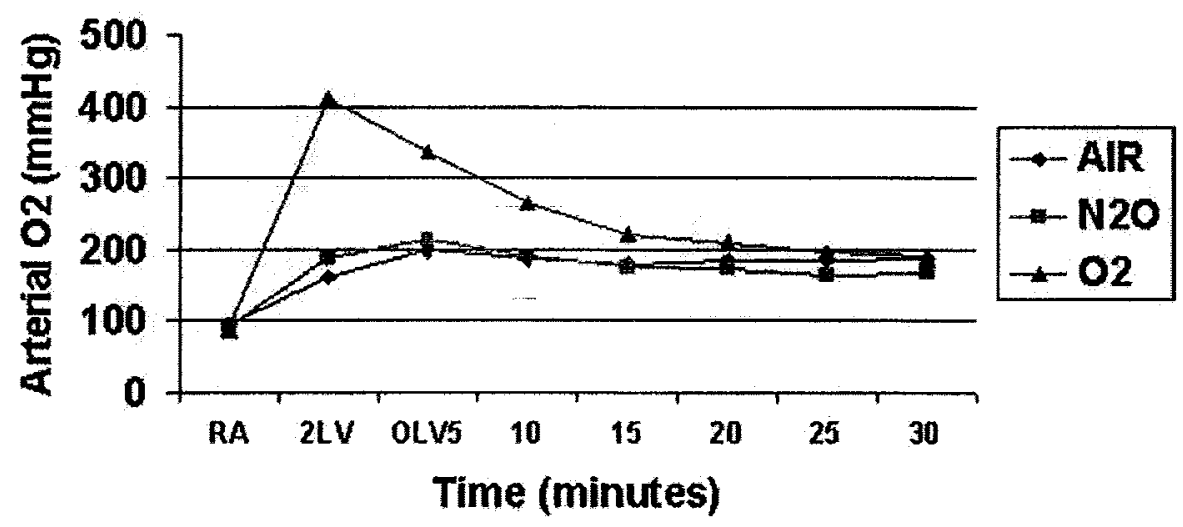

Figure 2. Mean $\mathrm{PaO}_{2}$ at the different study periods for the patients randomized to the AIR, nitrous oxide $\left(\mathrm{N}_{2} \mathrm{O}\right)$ and oxygen $\left(\mathrm{O}_{2}\right)$ groups. There were no differences in oxygenation among groups at baseline while breathing room air (RA, $\left.P=0.32\right)$. During two-lung ventilation (2LV) just prior to one-lung ventilation (OLV) $\mathrm{PaO}_{2}$ was significantly higher in the $\mathrm{O}_{2}$ group compared with the $\mathrm{N}_{2} \mathrm{O}$ and AIR groups $(P<0.001)$. After $5 \mathrm{~min}$ of OLV arterial $\mathrm{O}_{2}$ was higher in the $\mathrm{O}_{2}$ group compared with the $\mathrm{N}_{2} \mathrm{O}$ and AIR groups $(P<0.001)$. After $10 \mathrm{~min}$ of OLV $10 \mathrm{~min}$, arterial $\mathrm{O}_{2}$ was higher in the $\mathrm{O}_{2}$ group compared with the $\mathrm{N}_{2} \mathrm{O}$ and AIR groups $(P=0.005)$. No significant differences were observed in arterial $\mathrm{O}_{2}$ between the $\mathrm{O}_{2}$ vs $\mathrm{N}_{2} \mathrm{O}$ and $\mathrm{AIR}$ groups after $15,20,25$ or $30 \mathrm{~min}$ OLV.

difference in arterial oxygenation in the $\mathrm{O}_{2}$ group versus the other groups was still present after $15 \mathrm{~min}$ of OLV, but the differences were not significant after correcting for repeated measures $(P=0.04)$. There were no differences among the $\mathrm{N}_{2} \mathrm{O}$ and AIR groups. There were no subsequent differences in mean $\mathrm{PaO}_{2}$ values between groups to the end of the study period. Clinically important desaturation $\left(\mathrm{SpO}_{2}<90 \%\right)$ requiring alveolar recruitment maneuvers occurred in a small minority of patients with a similar incidence in each study group (AIR $n=2, \mathrm{~N}_{2} \mathrm{O} n=2, \mathrm{O}_{2} n=1$ ). No patient required discontinuation of OLV.

\section{DISCUSSION}

Lung collapse facilitates intrathoracic surgical procedures and is particularly important in minimally invasive thoracoscopic surgery and for patients with chronic obstructive pulmonary disease who have delayed lung deflation secondary to decreased lung elastic recoil. This study was designed to determine whether the type of inspired gas mixture used during two-lung anesthesia had an effect on lung collapse and oxygenation during OLV. Previous studies demonstrating that the use of nitrogen-containing air in the inspired gas mixture delays atelectasis during $2 \mathrm{LV}$ suggest that during OLV the nonventilated lung would also be subject to the same effect. ${ }^{2,3,5}$ This would theoretically delay collapse of the operated lung and thus worsen surgical conditions. Indeed, the results of the present study show that the use of air $/ \mathrm{O}_{2}$ during $2 \mathrm{LV}$ was detrimental to lung collapse 10 and $20 \mathrm{~min}$ after initiation of OLV.

During OLV with an open chest, the nonventilated lung collapses initially due to elastic recoil, which quickly brings the lung down to its closing capacity. Remaining gas in the lung is then removed by absorption into the pulmonary capillary blood. Reasons for the poor lung collapse during OLV include slow nitrogen uptake from the alveoli due to its low solubility $\left(\mathrm{N}_{2}=0.015 \mathrm{~mL} / \mathrm{dL}\right.$ blood vs $\mathrm{N}_{2} \mathrm{O}=0.47$ $\mathrm{mL} / \mathrm{dL})^{4}$ and possibly the effects of hypoxic pulmonary vasoconstriction, which decreases blood flow to the nonventilated lung further limiting gas uptake by the circulation. A modest improvement was noted in lung deflation in the AIR group from the 10-min to 20 -min time points. Since the study was only performed to $20 \mathrm{~min}$, the time at which the AIR group would have similar lung deflation scores to the other two study groups is unknown. Surgical exposure in the chest is dependent on the collapse of the nonventilated lung. Delaying lung collapse will impair surgical exposure and prolong the procedure. Facilitating lung collapse is particularly important in minimally invasive thoracoscopic surgery and in patients with smoking-related lung disease who may demonstrate gas trapping and reduced elastic recoil.

There was a significant difference between the $\mathrm{N}_{2} \mathrm{O}$ and $\mathrm{O}_{2}$ groups in lung deflation scores after $10 \mathrm{~min}$ of OLV (median collapse scores: $\mathrm{N}_{2} \mathrm{O}=9 / 10, \mathrm{O}_{2}=$ $7 / 10$ ). Both are gases with relatively rapid uptake from the alveoli. Pfitzner et al. ${ }^{1}$ suggest that a $50 \%$ $\mathrm{N}_{2} \mathrm{O} / \mathrm{O}_{2}$ inspired gas mixture leads to earlier collapse during OLV than a pure $\mathrm{O}_{2}$ mixture. This may be related, in part, to a "second gas" effect, whereby the rapid absorption of $\mathrm{N}_{2} \mathrm{O}$ would facilitate $\mathrm{O}_{2}$ uptake, or to a concentration effect or to the gas solubility. Similarly, Joyce et al. ${ }^{11,12}$ suggest that increasing the concentration of $\mathrm{N}_{2} \mathrm{O}$ in mixtures of $\mathrm{N}_{2} \mathrm{O} / \mathrm{O}_{2}$ will lead to a faster rate of collapse. The results of this current study corroborate this hypothesis based on our finding of more rapid lung collapse when $\mathrm{N}_{2} \mathrm{O}$ is included in the inspired gas mixture during $2 \mathrm{LV}$ prior to initiation of OLV. However, after $20 \mathrm{~min}$ of OLV, there 
was no significant difference in lung deflation scores between the two gases.

In the setting of ventilation with tidal volumes of 10 $\mathrm{mL} / \mathrm{kg}$, an $\mathrm{FIO}_{2}$ of 1.0 and without PEEP, there were no significant differences in the arterial oxygenation in any of the three study groups beyond 10 min of OLV. The significantly higher levels of $\mathrm{PaO}_{2}$ in the $\mathrm{O}_{2}$ group before this are of no clinical benefit. Upon initiation of $\mathrm{OLV}$, the $\mathrm{O}_{2}$ group had a higher mean- $\mathrm{PaO}_{2}$ than the other groups, which is not unexpected. However, despite starting from a higher $\mathrm{PaO}_{2}$, the progressive decline of $\mathrm{PaO}_{2}$ values during OLV suggest that, once OLV is initiated, the arterial $\mathrm{O}_{2}$ level is determined more by the $\mathrm{FIO}_{2}$ than the pre lung-isolation gas mixture. The gravitational gradient and fall of the mediastinum in the open chest during OLV may be more important factors in the formation of atelectatic regions of the ventilated dependent lung than the gas mixture used during the initial period of $2 \mathrm{LV}$ ventilation. It would seem intuitive that the application of PEEP would alter the development of atelectasis in the dependent, ventilated lung. However, during OLV, PEEP may contribute to an increase in shunting of blood flow away from the dependent, ventilated lung in some patients, depending on the individual lung mechanics and the presence of intrinsic or "auto" PEEP. ${ }^{13}$

Limitations of this study include the fact that the study period for lung collapse, before allowing surgical resection to proceed, was limited to $20 \mathrm{~min}$. Thus, it is not clear at what time the lung collapse would become equal among the groups. Another potential criticism is that the method of assessing lung collapse using the surgeon's rating scale was not completely objective and parametric. However, to use a more objective assessment, such as the distance of lung collapse away from the chest wall, would be clinically less relevant due to the differences in sizes of the patients' thoraces. The most clinically relevant assessment of the surgical access in the hemi-thorax is the surgeon's clinical impression, which was documented in this study. The majority of patients in this study had open thoracotomies, and the number of thoracoscopic procedures ( $\mathrm{AIR}=3, \mathrm{~N}_{2} \mathrm{O}=1, \mathrm{O}_{2}=2$ ) was too small to analyze as separate subgroups. It is not possible to be certain that these results can be extrapolated equally to patients having minimally invasive procedures, even though the physiology of one-lung anesthesia seems essentially the same for both types of surgery. The specific subgroup of thoracoscopic patients could be studied separately in the future. Another limitation is that the ability of nitrogen to decrease atelectasis in the ventilated lung and improve gas exchange during OLV may have been masked in the AIR group by switching to $\mathrm{FIO}_{2} 1.0$ during OLV. However, it is our standard clinical practice, and common in many other centers, to use an
$\mathrm{FIO}_{2}$ of 1.0 at the start of OLV to avoid potential hypoxemia.

In summary, deflation of the nonventilated lung during thoracic surgery is delayed if air is used as part of the anesthetic technique during the initial period of $2 \mathrm{LV}$. The use of $\mathrm{N}_{2} \mathrm{O}$ during $2 \mathrm{LV}$ will increase the initial rate of lung collapse compared with $100 \% \mathrm{O}_{2}$, but this effect is not significant after $20 \mathrm{~min}$ of OLV. Oxygenation during OLV with a $\mathrm{FIO}_{2}$ of 1.0 is independent of the gas mixture used during $2 \mathrm{LV}$. For thoracic procedures in which delayed collapse of the nonventilated lung will impede surgical exposure, the optimal anesthetic technique should include thorough de-nitrogenation of the lung which is to be collapsed, before OLV. Clinically, this can be done simply with ventilation using $\mathrm{FIO}_{2}$ 1.0, unless the patient has a specific contraindication to the use of a high $\mathrm{FrO}_{2}$, such as previous bleomycin therapy. ${ }^{14}$ After the initiation of OLV, techniques to avoid atelectasis in the dependent ventilated lung, such as recruitment, the titration of air in the inspired gas mixture, and possibly PEEP may then be useful.

\section{REFERENCES}

1. Pfitzner J, Peacock MJ, Pfitzner L. Speed of collapse of the non-ventilated lung during one-lung anesthesia: the effects of the use of nitrous oxide in sheep. Anaesthesia 2001;56:933-9

2. Browne DRG, Rochford J, O'Connell U, Jones GJ. The incidence of postoperative atelectasis in the dependent lung following thoracotomy: the value of added nitrogen. Br J Anaesth 1970; $42: 340-6$

3. Joyce CJ, Williams AB. Kinetics of absorption atelectasis during anesthesia: a mathematical model. J Appl Physiol 1999;86: $1116-25$

4. Joyce CJ, Baker AB, Kennedy RR. Gas uptake from an unventilated area of lung: computer model of absorption atelectasis. J Appl Physiol 1993;74:1107-16

5. Webb SJS, Nunn JF. A comparison between the effect of nitrous oxide and nitrogen on arterial pO2. Anaesthesia 1967;22:69-81

6. Agarwal A, Singh PK, Dhiraj S, Pandey CM, Singh U. Oxygenation in air ( $\mathrm{FiO} 20.4$ ) improves gas exchange in young healthy patients during general anesthesia. Can J Anaesth 2002; 49:1040-3

7. Myles P, Leslie K, Chan MT, Forbes A, Paech MJ, Peyton P, Silbert BS, Pascoe E. Avoidance of nitrous oxide for patients undergoing major surgery: a randomized controlled trial. Anesthesiology 2007;107:221-31

8. Senturk M. New concepts of the management of one-lung ventilation. Curr Opinion Anaesthesiol 2006;19:1-4

9. Tusman G, Bohm SH, Sipmann FS, Maisch S. Lung recruitment improves the efficiency of ventilation and gas exchange during one-lung ventilation anesthesia. Anesth Analg 2004;98:1604-9

10. Reid CW, Slinger PD, Lenis S. A comparison of the effects of propofol-alfentanil versus isoflurane anesthesia on arterial oxygenation during one-lung ventilation. J Cardiothorac Vasc Anesth 1996;10:860-3

11. Joyce CJ, Baker AB. What is the role of absorption atelectasis in the genesis of perioperative pulmonary collapse? Anaesth Intens Care 1996;23:691-6

12. Joyce $C J$, Baker $A B$, Parkinson R, Zacharias M. Nitrous oxide and the rate of gas uptake from an unventilated lung in dogs. Br J Anaesth 1996;76:292-6

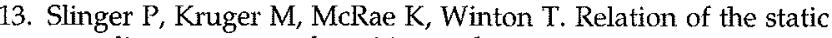
compliance curve and positive end-expiratory pressure to oxygenation during one-lung ventilation. Anesthesiology 2001;95: 1096-102

14. Mathes DD. Bleomycin and hyperoxia exposure in the operating room. Anesth Analg 1995;81:624-5 